\title{
Una comedia de muñecos de Constancio S. Suárez ${ }^{1}$
}

\author{
Rey Fernando Vera García \\ Maestría en Letras Mexicanas \\ rfernandovera@gmail.com
}

Resumen: En el siguiente trabajo se da cuenta de una pieza para títeres de Constancio S. Suárez, dramaturgo de corte popular, activo en la ciudad de México a principios del siglo xx. En una breve semblanza del autor, anotando los datos mínimos que se conocen sobre su vida se destaca su quehacer literario en la famosa imprenta de Vanegas Arroyo y en los diarios de la época. Posteriormente, se presenta la edición comentada de una de sus mejores obras para títeres o niños, El santo de mi papá, la cual gozó en su época de diversas ediciones. El propósito último de este trabajo es la difusión de la obra de un prácticamente desconocido dramaturgo popular mexicano, la cual puede situarse dentro de la historia general del teatro en México.

Авsтract: The following work gives account of a piece for puppets by Constancio S. Suárez, a popular playwriter active in México City at the beginning of the xxth Century. A biographical sketch of the author is given, writing down the scarce data that are known about his literary work both in the famous print of Vanegas Arroyo and in periodicals of his time. Secondly, there appears a commented edition of one of his best plays for puppets or children, El santo de mi $p a p a ́$, which was printed several times in his days. The ultimate purpose of this article is the diffusion of the work of a practically unknown Mexican popular playwriter, which can be included in the general history of theatre in México.

Palabras Clave: Dramaturgia popular mexicana; Teatro del Porfiriato; Teatro de Género Chico en México; Teatro.

Keywords: Mexican Popular Playwriting; Porfirian Theatre; Varieties in México; Theatre xxth Century.

FECHA DE RECEPCIÓN: 14 de noviembre de 2014.

FECHA DE ACEPTACIÓN: 21 de abril de 2015.

${ }^{1}$ El presente trabajo es posible gracias a una beca de la Coordinación de Estudios de Posgrado de la UNAM y se inserta en el marco de la investigación para la obtención del grado de Maestro en Letras Mexicanas titulada Perfil y Muestra del Teatro para Muñecos en México. Siglos XVIII al XX. 
Sombrío y enigmático autor, nacido probablemente durante el último cuarto del siglo XIX, publicó la mayor parte de su trabajo litera-
rio en la Testamentaria de Vanegas Arroyo. Sus trabajos, como muchos de los opúsculos de dicha imprenta, tuvieron una portada ilustrada por José Guadalupe Posada y quizá por ese detalle sea que lograron trascender en el tiempo.

John Nomland fue el primero en mencionar que varias de las piezas contenidas en Galería del Teatro Infantil, de la testamentaria Vanegas Arroyo, son, de hecho, obras de Constancio S. Suárez. Así por ejemplo, señala Sacrificio de amor, Un chasco furibundo, Los pulques mexicanos, Contra la corriente, Por Fingir Espantos y Fregoli (Nomland 1967: 25-29). Por su parte, Margarita Mendoza López es la segunda en mencionarlo como un autor mexicano de teatro; señala, además de las comedias ya citadas por Nomland, los siguientes títulos: Antes del baile, Caida y redención, El cura hidalgo, Honra y pobreza, Los muertos antes de muertos, Pasión eterna y Por Josefina (Mendoza López 1988). En último lugar, y de manera muy reciente, se publicó un artículo en el sitio Wikipedia donde se aborda la figura de Constancio S. Suárez. Resulta curiosa dicha entrada de la enciclopedia electrónica por estar escrita en alemán y no en español como era de esperarse; además, ofrece la localización de algunas ediciones contemporáneas publicadas en la revista Tramoya, publicación de la Universidad Veracruzana y la Rutgers University Camden. Salvo por este último detalle, el artículo no tiene ningún sustento documental y como sea no ofrece ningún dato relevante (“Constancio S. Suárez", en Wikipedia).

Así pues, la oscuridad que cubre la figura de $S$. Suárez resulta desconcertante, toda vez que el autor gozó de cierto prestigio como poeta en la prensa de su época e incluso se le llegó a reconocer un mediano éxito como autor teatral. Debió haber sido así, pues Ignacio B. del Castillo, sin dar cuenta de ningún documento que lo avale, afirma que nuestro autor solía firmar los trabajos que daba a la prensa con las iniciales C.S.S. (Castillo: 32). Desgraciadamente nosotros no hemos podido localizar ningún texto periodístico firmado con dichas iniciales. Y más aún, para nuestra sorpresa, ni Enrique de Olavarría y Ferrari, Armando de María y Campos o Luis Reyes de la Maza mencionan nada sobre el autor. Caso curioso este de Constancio S. Suárez de quien no existe mayor conocimiento sobre su vida ni obra, aunque de esta última y para desagravio nuestro, han llegado a nuestros días un nutrido 
número de sus piezas dramáticas, que no carecen de valor literario ni teatral a pesar de su sencillez.

Pero, como bien señala Eduardo Contreras Soto, "al hablar de la sencillez de estas obras, no deberíamos llegar, por ende, a una conclusión fácil pero superficial, de menospreciar o ignorar este repertorio". Esto porque como sea, el teatro de los jacalones, el teatro de aficionados o el teatro de títeres formaron parte de la inmensa oferta teatral de las primeras décadas del siglo $\mathrm{xx}$ y contribuyeron de una forma aún no plenamente estudiada, pero evidente, a la configuración de las distintas dramaturgias que vendrían luego. "Como una advertencia ilustrativa y significativa, podríamos incluir entre estas obras supuestamente sencillas a toda la producción de Constancio S. Suárez del que apenas conocemos haber sido escritor de planta de Vanegas Arroyo" (Contreras Soto: 18$)$.

En efecto, cierto es que gran parte de la obra dramática de Constancio S. Suárez fue publicada bajo la testamentaria de Vanegas Arroyo, sin embargo, no debe caerse en la peligrosa generalidad de algunos críticos que hacen de S. Suárez el autor de las docenas de papeles anónimos publicados por Vanegas Arroyo. Por las escasas evidencias documentales que tenemos, los legítimos trabajos de Constancio S. Suárez siempre se imprimían ostentando la firma de su autor.

Ahora bien, este escritor no fue un dramaturgo de escritorio, sino que estuvo involucrado en el ámbito teatral. Parece ser que conocía bien las dinámicas de la vida escénica popular y, es más, llegó a tener incluso algunas representaciones públicas no sólo en la capital, sino también en provincia, tal como lo atestigua la siguiente noticia, donde se anuncia la representación pública, por un grupo de aficionados, de la obra Caridad y redención en el marco de algunas celebraciones populares:

En uno de los más pintorescos sitios de Tixtla, fueron obsequiadas con una tamalada, por los señores filarmónicos, las señoritas que tomaron participación en la kermesse organizada para aquellos, el día de Santa Cecilia, patrona de los músicos. / El domingo 5 de diciembre se puso en escena, por una compañía de aficionados, el drama Caridad y Redención de don Constancio S. Suárez. Después del drama se representó el juguete cómico Los Pontalones. / Los productos líquidos de la función se destinarán a la beneficencia pública de la ciudad de Tixtla ("Guerrero", en La Patria, 11 de diciembre de 1909). 
En relación directa con su actividad literaria, Constancio S. Suárez también escribió poesía. Más allá del supuesto de redactar calaveritas y devocionarios para Vanegas Arroyo, lo cierto es que contaba con cierta aptitud poética. Sus trabajos fueron dados a la prensa. La manufactura de la composición está bien lograda y puede notarse un ejercicio preciso de la versificación. Como en el caso de algunos de sus trabajos dramáticos, su poesía pudo haber sido de corte romántico y con pretensiones metafísicas y religiosas. No es posible detenerse en el análisis completo de su poesía pues este no es el lugar adecuado, y, además, no poseemos sino dos sonetos publicados en 1904 que colocamos como evidencia de la obra y semblanza del autor ("Dos sonetos para el Diario del Hogar", en El Diario del Hogar, 22 de mayo de 1905):

\section{La luna y el alma}

Nace la luna con la faz sombría y ya le espera tenebroso velo: obscuras nubes cual crespín de duelo cercan su ruta silenciosa y fría.

Pasando va tras la nublada vía. Mas raya al fin en luminoso vuelo, y libre ya, por la región del cielo refleja pura el esplendor del día.

Así el alma también, desde la cuna, las desdichas enlutan su carrera $y$ atraviesa por ellas una a una.

Así se purifica y regenera hasta quedar como blanca luna, radiosa [sic] y libre en la brillante estera.

El sueño

\section{A Fernando de la Paz Álvarez}

Cual un consuelo del amor divino, el sueño pone su intangible beso al ser humano, que en la carne preso, está cumpliendo su fatal destino. 
Dulce caricia, aliento peregrino toca los ojos con amante exceso y desprendida del terreno peso, el alma busca sideral camino.

Feliz y libre con delicia siente afán sublime de escalar la altura, y vuela por el éter transparente.

Mil goces halla, sin igual ventura y a Dios vislumbra entre la luz ardiente del estrellado cielo que fulgura.

UNA PIEZA PARA MUÑECOS. EL SANTO DE MI PAPÁ, OBRA Y COMENTARIO

El santo de mi papá es un sainete costumbrista, compuesto por 214 versos preponderantemente octosílabos de rima asonante. La forma que persiste en toda la pieza es el romance. Algunos de los versos no alcanzan el número de sílabas exacto, pero se compensan dado que mantienen el ritmo de la pieza. Existen otros versos de 4 sílabas que suponemos debieron ser parte de veloces pasajes hablados. Siendo en verso la composición, asumimos que sugería un acompańamiento musical durante prácticamente toda la obra. El pie de imprenta señala 1909 como el año de publicación del libreto. La pieza, debido a su versatilidad, también fue incluida en la colección El placer de la niñez, colección completa de comedias para jóvenes y señoritas, sin fecha, colección formada por obras de $S$. Suárez exclusivamente y publicada en la testamentaría Vanegas Arroyo. No ha sido posible encontrar constancia documental acerca de representaciones públicas, pero debieron existir, al menos en ámbitos privados y en teatro de aficionados, pues la pieza tuvo varias impresiones.

En cuanto a la fábula, El santo de mi papá recrea el diálogo entre dos jovencitos, Albertito de 10 años y Rosaura de 12. El primero ha invitado a la segunda a su casa para mostrarle sus juguetes nuevos, mientras pasa el tiempo encerrado en su alcoba, debido a que en la sala se celebra el cumpleaños de su padre, don Pompeyo, un hombre de alta estima que ha sido visitado por una considerable cantidad de personas. Rosau- 
ra llega tarde a la cita, pero tan pronto aparece, asume su labor como compañera de juegos, soportando todas las desavenencias y groserías que al ladino de Albertito se le van ocurriendo. Los maltratos del muchacho se van mezclando con su arrogancia y presunción. Conocemos entonces que ambos chiquillos forman parte de estratos sociales diferentes y que Rosaura realmente hace el papel de criada de Alberto. Luego de los juegos, ambos chiquillos comienzan a aburrirse, es entonces cuando a Alberto se le ocurre preguntar si acaso a ella le gustaría "tomar una copa”. Rosaura, que se había mantenido recatada, puntualiza que mientras la copa "sea de vino" ella no tiene inconveniente. Puestos de acuerdo, por fin, en un juego que agrada a ambos, Alberto sale disparado hacia la sala, donde no debería estar, para hacerse de una botella de coñac de las muchas que hay sobre la mesa. En poder de los chiquillos, la botella comienza a vaciarse entre bromas y disparates, hasta que finalmente la han consumido y ambos niños terminan por completo ebrios.

La comedia está dividida en seis escenas determinadas por la entrada de los personajes en diferentes momentos de la obra. Siendo una comedia de costumbres, ninguno de los caracteres de los niños está plenamente desarrollado, sino que corresponden a acciones tipificadas y en consonancia con la imagen que se tenía de los niños a principios de siglo xx. A propósito, vale señalar una vez más que el epíteto de comedia de niños no debe tomarse de manera literal, interpretando que se trata de teatro dirigido a la infancia. Como hemos ya explicado, son comedias para ser representadas por títeres, niños o jóvenes para solaz y entretenimiento de adultos. Ciertamente, existen marcas de picardía y doble sentido en la comedia que no aparecen en la primera literatura especialmente dedicada a la infancia, por muy popular que esta fuera, entonces no puede ser éste ejemplo de teatro infantil. Una de las marcas dentro de la comedia, la más evidente, es la embriaguez de los nińos; y la segunda, el juego del torito, que se inicia con la inocente e ingenua advertencia de Albertito de ser un juego muy simpático, tanto que incluso sus padres lo llevan a cabo. Considero que no es necesario explicar el doble sentido del juego (vv. 88-97).

Junto con Por fingir espantos, El santo de mi papá es otra de las comedias de S. Suárez que usan al niño como personaje. Dentro de la dramaturgia del autor, así como dentro de la literatura dramática en general, pero en particular sobre la popular para muñecos, esto es significativo, pues si bien todas las obras con las que componemos nuestro 
corpus anuncian ser para niños o títeres, tan sólo estas dos de S. Suárez, Policarpito y A fotografía instantánea de Ildefonso T. Orellana, le dan voz por completo a los personajes nińos. Sin embargo, dicha voz corresponde a la imagen que se tenía de la infancia en los primeros años del siglo xx. María Eugenia Negrín ha inventariado las múltiples voces y cualidades que se hacen de los nińos en la literatura. En general, llega a afirmar que se tenía una imagen extremista de la figura de la infancia. La primera correspondía con un nińo angelical dotado de virtudes enteramente buenas y la otra, la de un niño perverso de comportamiento inadecuado y socialmente reprobable. Aunque, a decir verdad, de esta última caracterización ofrece pocos ejemplos, pese a que fue una de las imágenes más socorridas durante principios del xx (Negrín Muñoz: 198-228).

Siendo un sainete costumbrista, uno de los objetivos del Santo de mi papá sería reflejar mediante la caricatura y la parodia el comportamiento de la sociedad, a través de la exposición cruda y grotesca de los vicios humanos. El hecho de mostrar la embriaguez de los niños tiene la función de acentuar la iniquidad de los adultos mediante el asombro e indignación que podría caber en la representación de niños malcriados con comportamientos impropios a su edad. De algún modo, la fractura del estereotipo del niño como un ser bueno y angelical crea una tensión dramática cuyo objetivo primordial es la reprimenda moral del adulto espectador. Todo esto se realiza mediante el juego y la risa, lo cual si bien suaviza el discurso, pues no se trata de una apología, sino de un divertimento, también vuelve el discurso mucho más efectivo. Pero también debe pensarse que como sainete, El santo de mi papá podría tomarse como un texto documental de los problemas sociales de la época. Ciertamente que el tono de la comedia es intimista y que el cuadro revela un ambiente estrictamente privado de una familia de la clase media culta porfiriana y/o de la calle, pero tomando en cuenta que la pieza se montaba en ambientes festivos precisamente de esta clase social, entonces los espectadores recibían plenamente el mensaje y podían centrar su atención en la censura que en la pieza se hace de su comportamiento como individuos o de su postura hacia la infancia.

Ya desde el siglo XIX, en la narrativa costumbrista se menciona con cierta alarma la tendencia de los grupos de nińos a volverse delincuentes y borrachos. María Eugenia Negrín, en este sentido, cita pasajes de "La mesa chica" de Ángel de Campo en que un grupo de chiquillos y 
adolescentes son desplazados y relegados a la parte menos accesible de la casa para que no interrumpan las reuniones sociales de los adultos. Aún así, se dan sus mañas para hacerse de buenos confites y pasteles y por su puesto vinos y coñac, que son su mayor proeza (Negrín Muñoz: 223). Por cierto que vale la pena decir que este texto de Ángel de Campo tiene cierta afinidad temática y de caracterización de los niños con El santo de mi papá. En ambas obras los niños son desplazados, retirados de las reuniones importantes, las de los adultos, por temor a su comportamiento y villanía; además, en ambos relatos, el niño se muestra ladino y sumamente inteligente, pues conoce la manera de evitar todos los castigos y granjearse, como si de un botín se tratara, de los mejores manjares de la mesa. Veamos:

Pedro y Antonio, enojados porque se les había expulsado ignominiosamente de la congregación de los formales, se aislaban en un rincón improvisando su mesa en una silla y escondiendo debajo de un viejo tocador el fruto de robos disimulados: rebanadas de queso y de jamón, no pocos pasteles, frutas secas y hasta media botella de coñac (Campo: 10).

Por su parte, en El santo de mi papá ocurre una acción parecida a la descrita por Micrós, tomando en cuenta que a Albertito su padre lo envía a su cuarto, como medida ante su comportamiento inadecuado. Y de ahí, el robo de la comida representa una suerte de venganza ante el desplante del padre, pero también una reivindicación a su dignidad y orgullo, pues si el santo del padre está siendo magnífico, en cambio el suyo apenas tuvo presencia, sin decir que lo que más recuerda es la azotaina que le dieron por malcriado. Por esta razón, el robo del coñac está justificado (vv. 129.153).

Por otra parte, la forma del sainete de la pieza nos hace preguntarnos sobre el contenido social que pudiera tener. El aspecto, sin duda, que más resalta es el comportamiento y la caracterización de los personajes niños que representan. Así pues, Rosaurita es la representación de la criada de juegos o compañera de juegos. Era costumbre en la época que los hijos de la servidumbre de una casa terminaran sirviendo a los más pequeños de la misma, a veces como verdaderos sirvientes y otras como amigos forzados, dado el sueldo de sus padres. Estos compañeros de juegos se encargaban de hacer compañía y entretener a los infantes 
amos de la casa y algunas veces se les otorgaba una educación y cuidado similar a la de sus amitos.

Es evidente que Alberto y Rosaura pertenecen a clases sociales diferentes. Alberto es el hijo mimado de don Pompeyo, un respetable hombre de clase media alta, mientras que Rosaurita es la criada de juegos, pobre, contratada especialmente para evitar que el niño tome rumbos ajenos a su formación y posición social, aunque de nada sirve, pues no necesita de amigos del "colegio" para aprender mañas y hacer fechorías, los criados de su casa le sirven de mentores al respecto. Sabemos que Rosaurita ejerce un contraste extremo con relación a Albertito, pues la niña se asombra de la diversidad de juguetes de su amigo (vv. 77-86).

La dinámica que existía entre los niños de clases sociales distintas consistía en la protección que los ricos ejercían sobre los pobres (Castillo Troncoso: 83-112). Y aunque, de alguna manera, la pobreza era sinónimo de perversión y debía ser erradicada mediante el apoyo de los que más tenían, lo cierto es que, en la comedia, existe la impresión de la pobreza como depositaria de los más altos valores morales. El padre de Alberto no permite que éste se junte con compañeros del colegio, pues conoce de antemano que son unos granujas; en cambio, de Rosaurita, la compañera de juegos, no puede sospechar nada, cuanto más que es niña. Aquí ocurren dos cosas importantes de señalar que generan la tensión dramática de la pieza y la extrañeza del público. Por una parte, se cree antes de la escena que Alberto es la imagen tradicional del niño puro, asexuado, bueno y obediente y por la otra que Rosaurita, al ser pobre y desprotegida no puede albergar pensamientos inicuos. Pero al transcurrir la pieza esto se revela como falso: Alberto es un chico sumamente travieso y grosero, y Rosaura, pese a su recato y buen comportamiento, termina por incitar al jovencito a robar el coñac.

El otro aspecto social a resaltar de la comedia es el consumo de alcohol por parte de los niños. Ya en los años en que se publica la comedia, había ciertas voces escandalizadas por el consumo de alcohol entre los niños. Era habitual, sin embargo, que se comenzara a ingerir bebidas embriagantes durante la niñez, pues no existían leyes efectivas en contra de la práctica. Así por ejemplo, en 1904, la prensa de la ciudad de México traía a la capital la indignante noticia de un periódico de Guaymas sobre el alcoholismo en menores de edad. Curiosamente no señala a los padres como responsables, sino al Estado, a través de la policía que no sabía poner orden en el asunto: 
Se queja un periódico de Guaymas del horroroso incremento que está tomando en aquel puerto la embriaguez en los menores de edad y culpa muy especialmente a la policía que permite la entrada de los menores a las cantinas y a los dueńos de los referidos establecimientos. El mal parece que es general, pues aquí es común y corriente ver a cada paso, principalmente los días de fiesta, a muchos menores iluminados por el alcohol y hablando un lenguaje capaz de ruborizar el pudor más empedernido. El correctivo de ese desbordamiento, no es ni puede ser otro que una activa y eficaz vigilancia por parte de la policía e imponer penas severas pero durísimas a los cantineros que vendan a los menores licores embriagantes (“Niños Borrachos", en La Patria, 21 de abril de 1904).

En efecto, el consumo de alcohol entre menores era general en toda la República y aún más en la ciudad de México, donde el contraste entre clases estaba (y sigue estando) dolorosamente marcado. Luis G. Urbina en 1913 focalizaba el consumo de alcohol entre los menores de clases sociales bajas, debido a que sus padres, en su ignorancia casi bestial no podían hacer otra cosa sino corromper a sus hijos permitiéndoles el "pulque", bebida sin la cual la miseria de sus vidas no podría ser llevadera:

¡Cómo! ¿Hay niños borrachos, y son los padres los que ponen en sus manos temblonas el primer vaso de pulque, y en sus cerebros, todavía inconscientes, el primer deseo de hallar en la embriaguez un regocijo? Sí, hay niños borrachos y son los padres los que se dedican a esas diabólicas enseñanzas. Pueden verse en la calle los efectos de esta abominable perversidad. Van por esos mundos raquíticos, escrofulosos, endebles, muchos chiquillos que llevan marcado el estigma de su origen, la huella repugnante de la miseria y del vicio de quienes les dieron el ser. Estos infelices no pidieron la vida, y no reniegan de ella, sino que la soportan y hasta suele parecerles placentera (Urbina 1913).

Ciertamente que el consumo de alcohol, como hasta nuestros días, no era exclusivo de los estamentos bajos de la sociedad. Como ya lo ejemplificamos con la cita de Ángel de Campo ("La mesa chica"), entre las familias de la clase media era algo frecuente, y también entre escolares de la época; así lo atestigua una carta de cierto maestro de escuela, don Donato Martínez, enviada a la redacción de El Siglo Diez y Nueve 
con motivo de la acusación que se le hace de haberse encontrado un par de estudiantes alcoholizados en su escuela a la hora de salida:

Acerca de los niños borrachos que se encontraron en la escuela, espero que pruebe que se encontraron en la escuela, por quién, cuándo y a qué hora: le hago el [en] cargo anterior y voy a referir lo acontecido: el jueves 11 de mayo del año pasado, faltaron a la escuela por la tarde los niños Pedro García, Felipe Valdovinos y Amado Hilario. A las cinco trataron de incorporarse con los otros que salían, para no hacer notable su falta, pero los que asistieron, viendo que no estuvieron presentes y sabiendo que se les había anotado en el registro de faltas y más que todo, causándoles novedad o más bien escándalo, el estado de embriaguez en que se hallaban, cuando salía me dieron parte de la ocurrencia en la misma calle ("Remitido", en El Siglo Diez y Nueve, 7 de abril de 1844).

Es precisamente en el escándalo que causa ver a dos menores bebiendo hasta la embriaguez y solazándose de ello en lo que está basado el humor de El santo de mi papá. Ciertamente el tema está más cercano con el costumbrismo del teatro popular que con el didactismo del primer teatro para niños. De ahí que sigamos insistiendo en que no se trata de un teatro infantil, sino para públicos adultos.

\section{Nuestra EDición}

Siendo el propósito primordial de este trabajo la difusión de uno de los más brillantes dramaturgos del teatro popular de principios del siglo $\mathrm{xx}$, es entonces que hemos querido presentar una edición reformada para un público actual. Así pues, se ha actualizado tanto la ortografía como el uso de signos de puntuación. En corchetes se colocan los añadidos. Sin embargo se ha conservado la disposición y sentido de las acotaciones que escribió el autor. 


\section{Hemerobibliografía CitAdA}

\section{Fuentes primarias}

"El imitador de Frégoli", en El Correo Español, México, 31 de enero de 1897.

"En el Renacimiento", México, 06 de noviembre de 1901.

"Frígoli", en La Patria, México, 18 de octubre de 1901.

"Guerrero", en La Patria, México, 11 de diciembre de 1909.

"Niños Borrachos", en La Patria, México, 21 de abril de 1904.

Suárez, Constancio S. "Dos sonetos para el Diario del Hogar", en El Diario del Hogar, México, 22 de mayo de 1905.

"Remitido", en El Siglo Diez y Nueve, México, 7 de abril de 1844.

Urbina, Luis Gonzaga. "Los niños ebrios", en El Abogado Cristiano Ilustrado, México, 4 de diciembre de 1913.

\section{Fuentes secundarias}

CAmpo, Ángel de. "La mesa chica", en Material de lectura 1. México: Universidad Nacional Autónoma de México, 2007.

Carballido, Emilio. Teatro para obreros. México: Editores Mexicanos Unidos, 1984.

Castillo, Ignacio B. Del. "Catálogo de seudónimos, anagramas, iniciales, etc., de escritores mexicanos y de extranjeros incorporados a las letras mexicanas", en Boletín de la Biblioteca Nacional. México, Segunda época, núm. 4, 1953.

Castillo Troncoso, Alberto del. "Imágenes y representaciones de la niñez en México a principios del siglo xx", en Aurelio de los Reyes (coordinador). Historia de la vida cotidiana en México, V, volumen 2. México: Fondo de Cultura Económica / El Colegio de México, 2006: 83-112.

"Constancio S. Suárez", en Wikipedia <http://de.wikipedia.org/wiki/Constancio_S._Su\%C3\%A1rez> (fecha de consulta: 10 de septiembre de 2014).

Contreras Soto, Eduardo. "A caballo entre mundos y estilos. Las dramaturgias y sus vidas escénicas en los inicios del siglo xx”, en David Olguín (coordinador). Un siglo de teatro en México. México: Consejo Nacional para la Cultura y las Artes / Fondo de Cultura Económica, 2011.

María y Campos, Armando de (Prólogo). Teatro mexicano de muñecos. 25 piezas de teatro guiñol. México: Ediciones Encuadernables El Nacional, 1941. 
Mendoza López, Margarita. Teatro mexicano del siglo XX: catálogo de autores mexicanos. México: Instituto Mexicano del Seguro Social, 1988.

Negrín Muñoz, María Eugenia. "En el limbo decimonónico. El niño y sus espacios en la narrativa mexicana”. Tesis. Doctora en Letras Mexicanas. Universidad Nacional Autónoma de México, 2002.

\section{EL SANTO DE MI PAPÁ}

Diálogo para niños ${ }^{2}$

Personajes

Alberto de 10 años de edad

Rosaurita de 12 años de edad

La escena en México, época actual

\section{Acto único}

Cuarto de Alberto, con puerta al fondo y otra a la izquierda. Sillas y mesitas y muchos juguetes. Es de dia.

\section{Escena I}

Alberto asomándose por la puerta izquierda

[Alberto:] ¡Caramba, cuánta visita

tiene ahora mi papá!

Como que es hoy su cumpleaños

y le vienen a colgar. ${ }^{3}$

(Va al centro del foro)

5

También a mí me colgaron,

pero no es de comparar

los regalos que me hicieron

con los que en la sala están.

El onomástico mío

10

fue regular nada más.

${ }^{2}$ Debe entenderse que es una pieza para ser representada por actores niños para públicos adultos. No se trata de Teatro Infantil.

${ }^{3}$ En desuso, obsequiar (DRAE). 
Muchos juguetes me dieron pero poco de tragar. Sólo unos cuantos pasteles que estaban con harta sal; de fruta, pues casi nada, pero eso sí, por estar haciendo daños, me dieron una azotaína cabal.

Pero ya no hay que acordarse de ese momento, ¡caray! Hoy se trata del jolglorio, de divertirme y no más. Ahora no voy al colegio. Pues es claro, ni pensar. Ni mañana voy tampoco, que fingiré enfermedad. Y así me doy ya dos días de descanso y de jugar. Rosaurita no dilata que a acompañarme vendrá, la única con quien juego porque amigos, ¡qué capaz! A mi papá no le gusta porque dice muy formal que me enseñan picardías y me pueden maltratar. Como si yo no aprendiera más mañas que Satanás con los criados y las criadas que sirven a mi papá. ¿A qué hora vendrá Rosaura? Las once ya van a dar y me ofreció que a las diez ya estaría por acá. Pero oigo ya sus pasitos. (Se asoma por la izquierda) Sí, sí, ella es ni qué dudar. 


\section{Escena II}

Alberto y Rosaura

Rosaura: ¡Buenos y muy buenos días!

¿Qué tal te ha ido Albertito?

Alberto: Bien, Rosaura, ya lo ves

50 ya te esperaba muy listo.

Rosaura: ¿Verdad que se me hizo tarde?

(Viendo los juguetes)

¡Qué juguetes tan bonitos!

Alberto: Por orden voy a enseñártelos.

(Enseñando los juguetes)

Tienes aquí un caballito,

55 que sólo le falta hablar.

Rosaura: Qué ocurrente eres chiquillo.

¿Pues que los caballos hablan?

Alberto: Pero ladran muy bonito

Rosaura: Relinchan querrás decir.

60 Alberto: Eso sí, eso lo mismito.

Un cañoncito de bronce, con cureña ${ }^{4}$ de platino.

(Le enseña el cañoncito)

Esta caja de soldados.

(Le muestra la caja)

Rosaura: $\quad$ Es un batallón de gringos.

65 Alberto: Estas tres pelotas de hule y este mono fusilito.

Rosaura: ¡Ay! ¿pero que es de deveras?

Alberto: $\quad$ Es para puros casquillos. ${ }^{5}$

(Enseña lo que va diciendo)

Mira este oso, ¡qué gordote!

70 Rosaura: Pues parece que está vivo.

${ }^{4}$ El DRAe señala: Armazón compuesta de dos gualderas fuertemente unidas por medio de teleras y pasadores, colocadas sobre ruedas o sobre correderas, y en la cual se monta el cañón de artillería.

${ }^{5}$ Casquillo, parte vacía del cartucho (DRAE). 
Albero: $\quad$ Este payaso de barro para que hagamos un circo.

Rosaura: ¡Qué cara tan ocurrente!

Alberto: Ahora mira este changuito.

Se parece a mi papá.

Rosaura: ¡Qué malo eres Albertito!

Alberto: Tengo muchos que enseñarte y no es cuestión de ratito. Vamos mejor a jugar.

80 Rosalba: ¿Quién te dio estos juguetitos?

Albertito: Me los mandó de París mi padrino de bautizo.

Rosalba: Bastante le habrán costado.

Alberto: Allí son muy baratitos.

A jugar pronto se ha dicho.

Rosalba: Bueno, bueno, pero ‘̇a qué?

Alberto: Pues hombre, que sea al torito.

Rosaura: ¡Ay, ese juego tan feo

y que se dan tantos brincos, tan vulgar y tan chocante!

Alberto: ¡Chocante! ¡Si es tan bonito!

Si hasta mi papá lo juega.

Rosaura: Eres un embusterillo.

95 Alberto: Palabra de honor, Rosaura.

Hace mi papá de bicho

y mi mamá lo torea,

si es de lo más divertido.

Anda, vamos y verás.

100 Rosaura: ¡Ay, no, porque me fatigo!

Alberto: Por eso no va muy breve, sino que muy despacito. Tú eras Gaonita, ${ }^{6}{ }^{\text {¿estás? }}$

${ }^{6}$ Debe de tratarse de Rodolfo Gaona Jiménez (1888-1975), torero nacido en León de los Aldamas, Guanajuato, que para la fecha de publicación de la comedia, 1909, era ya un torero con bastante buena presencia en el país. Existió, en efecto, también un torero de nombre José Ramírez Gaonita, nacido en la ciudad de Chihuahua en 1898, 
Y yo un toro muy revivo.

105 Rosaura: Mejor vamos a otra cosa.

Alberto: Aunque sea sólo un ratito.

(La torea con una mascada)

¡Éntrale, éntrale, anda!

(Juegan al toro. Rosaura con desgana.)

Alberto: Listo.

Rosaura: Mejor a otra cosa, Alberto.

$110 \quad$ A la pelota es bonito.

Alberto: ¡Ah! Una suerte de magia

que me enseñó ayer mi primo.

Fíjate mucho Rosaura.

(Saca un quinto del bolsillo)

Aquí tenemos un quinto.

(Lo hace)

115

Me lo echo aquí en esta mano

y... puf, ha desaparecido.

(Sopla la mano cerrada que tiene el quinto y la abre)

Rosaura: Ya hombre, ya te lo cogí.

Alberto: No es posible; soy muy vivo.

Rosaura: Te lo has echado en la manga.

120 Alberto: Eso no es cierto.

Rosaura: Ciertísimo.

A ver, sacudo y verás.

(Quiere sacudirle la manga)

Alberto: No, no que está prohibido.

Rosaura: Mira, mira, tramposote.

(Le sacude la manga y cae el quinto)

125 Alberto: Me la cogiste deveras.

Pero es porque no estoy listo, me falta que yo la ensaye.

Rosaura: ¡Ah, qué chambón suerterito! ${ }^{7}$

Alberto: ¿Quieres tomar una copa?

130 Rosaura: Sí, pero que sea de vino.

pero para la fecha de publicación de la comedia, tenía tan sólo 11 años. El debut de este torero no se dará sino hasta 1919. Por lógica, debe tratarse del primero.

${ }^{7}$ Neologismo, sustantivo en diminutivo de la palabra suerte, truco, magia 
Alberto: Espérame; ahora verás, a ver qué cosa me pillo.

Escena III

(Se va por el fondo)

Rosaura sola, se asoma al fondo

[Rosaura:] Por fortuna no hay ninguno

135 que pudiera ver a Alberto.

Ya, ya tomó una botella, es coñac de cinco ceros. ${ }^{8}$

Nos vamos a emborrachar, o a alegrarnos por lo menos.

\section{Escena IV}

Dicha y Alberto con una botella de coñac que saca de debajo del saco

Alberto: Este licor es magnífico,

140 un cońac de lo muy bueno.

Rosaura: ¿Y qué tal que se nos suba?

Alberto: Entonces lo bajaremos, aquí a boca de botella por mi papá brindaremos.

145 Rosaura: Anda, búscate una copa.

Alberto: Así nomás; ya no hay tiempo, que pudiera verme alguno $y$ entonces quedaba fresco.

Rosaura: A ver, pues, lo probaré.

(Toma la botella y bebe un trago, tosiendo y queriéndose ahogar)

${ }^{8}$ Cońac de cinco ceros y catorce unidades era una bebida embriagante fabricada a partir de la combinación de aguardiente de uva (brandy) con una porción mínima de cońac francés. No se trataba realmente de una bebida adulterada, sino de una imitación de Cognac. También pudo haber sido hecha a partir de sustancias químicas, pero se desconoce el procedimiento. Tomás de Cuéllar lo menciona en el capítuo VIII de su novela Baile y cochino como una bebida de ínfima clase, aunque la bebida ciertamente no se asociaba con las clases bajas, pues tal parece que no era nada barato, sino más bien con aquellas personas que deseaban agasajarse con un licor sin que en ello se les fuera la fortuna. 
150

¡Ay, ay! ¡Uf, uf, uf! ¡Qué feo!

Alberto: $\quad$ (Le soba el pecho) ¿Ya te pasó, Rosaurita?

Rosaura: ¡Ay! ¡Cómo me arde el pescuezo!

Alberto: Ahora voy yo, presta acá.

(Toma la botella y bebe)

¡Caramba, si está muy bueno!

155

Tú no estás acostumbrada

por eso te hizo ese efecto.

Bebe otro trago, despacio.

(Le da la botella y Rosaura bebe)

Rosaura: Ahora sí, pasó ligero.

(Alberto le quita la botella)

[Alberto:] Yo brindo por mi papá

160

que es el señor don Pompeyo

y por ser su santo es justo

que el gañote refresquemos.

Sí, que viva muchos años,

mi papá, yo le deseo.

165 Rosaura: Bien, bien está muy precioso

ese brindis, sí muy bueno.

(Aplaude a Alberto)

Trae acá que a mí me toca.

(Toma la botella y brinda)

Con muchísimo contento, voy a beber este trago

170

por el señor don Pompeyo

porque viva siempre gordo,

tan regordo como puerco

y porque te zumbe muchos

con su cinturón de cuero.

175 Alberto: Eso sí, no me gustó.

Tu brindis está muy feo

y en lugar que yo te aplauda

te silbo mucho y muy recio.

$(\text { Le silba })^{9}$

${ }^{9}$ Dato curioso: era frecuente en los teatros alzar alharaca de rechiflas cuando alguna obra, escena o función no gustaba. 
Rosaura: ¡Cállate, hombre, que me aturdes!

180 Alberto: ¿Pues para qué dices eso?

Rosaura: Bebe más, ten la botella.

Alberto: (Bebe) Está muy rico, muy bueno.

Lo que es hoy, yo me emborracho

y pésele al mundo entero.

185 Rosaura: Róbate unos pastelitos.

Alberto: Dices bien, ahorita vengo.

Escena V

(Se va por el fondo)

Dicha y Alberto con un alcatraz ${ }^{10}$ de pastelitos

Alberto: Aquí está ya el pastelazo.

Rosaura: A ver, a ver, trae acá.

Alberto: ¿Porque tienes tú dos bocas?

190 Rosaura: Porque borracho ya estás.

Alberto: (En voz baja) ¿Yo borracho? Ni lo digas.

Que vaya a oír mi papá.

Rosaura: A ver un pastel grandote.

(Toma un pastel y se lo come)

Alberto: De veras no puedo andar.

195 Todo vueltas me está dando.

Rosaura: También yo estoy incapaz.

Alberto: Voy a comerme un caballo

y mi pastel a montar.

Rosaura: A borracho me ganaste

200 que al revés hablaste ya.

Alberto: Tú eres la que está al revés.

Rosaura: Otro trago de cońac.

Alberto: Cómete hasta la botella, que en el comedor hay más.

205 Rosaura: (Bebe) Ya llegas al techo tú, ¿por qué te alargas, caray?

Alberto: $\quad$ Los dos estamos trompetos. ${ }^{11}$

Rosaura: Con tinta se quitará.

${ }^{10}$ De la voz alcatraz, cucurucho o capirote de papel.

${ }^{11}$ Coloquialmente, estar borracho, estar o andar trompeta. 
(Toma un tintero y se lo vacía a Alberto)

Alberto: ¡El coñac me estás echando!

210 Rosaura: No, hombre, no es coñá.

Es que ya voy a dormirme.

Alberto: Y yo lo mismo ¡A roncar!

Que así debe celebrarse

el cumpleaños de papá.

(Se quedan en sus sillas dormidos)

Telón 